\title{
Practise what you teach: Lessons learnt by newly appointed lecturers in medical education
}

C van Wyk, ${ }^{1} \mathrm{PhD}$ (Health Professions Education), MSc (Med) Genetic Counselling; M M Nel, ${ }^{1} \mathrm{PhD}$ (Tertiary Education Management), BEd, PhD (Anatomy); G J van Zyl, ${ }^{2}$ MB ChB, MFamMed, Postgrad Dipl Health Administration, Postgrad Dipl Community Health, MBA, PhD (Health Professions Education)

\author{
${ }^{1}$ Division Health Sciences Education, Office of the Dean, Faculty of Health Sciences, University of the Free State, Bloemfontein, South Africa \\ ${ }^{2}$ Faculty of Health Sciences, University of the Free State, Bloemfontein, South Africa
}

Corresponding author: C van Wyk (vanwykc2@ufs.ac.za)

\begin{abstract}
Background. This article reports on research conducted on the orientation, support and continued development of lecturers in medical education, which took place at a South African (SA) university.

Objectives. To provide insights that are relevant for faculty developers and senior leadership, and evidence for reconsidering approaches to faculty development initiatives for newly appointed lecturers.

Methods. New lecturers' experiences of a well-established orientation course were explored qualitatively using focus group interviews. Participants' responses were transcribed and analysed thematically.

Results. On entering the programme, participants generally reported having no or little prior teaching experience. Participants' experiences revealed that an orientation structure is context sensitive and a centralised approach strengthened collegial relationships, but that decentralisation could be considered in medical education orientation. We found that education instruction that allows for active engagement between instructors and peers elicited positive responses. Furthermore, our approach to orientation cultivated a sense of accountability in new staff members to continue their participation in faculty development.

Conclusions. The findings suggest that successful and up-to-date orientation initiatives are indispensable. However, more research should be done in our context and we recommend collaborating with other SA universities in future research endeavours.
\end{abstract}

Afr J Health Professions Educ 2019;11(2):47-52. DOI:10.7196/AJHPE.2019.v11i2.1115

The staff of an institution is said to be its most valuable asset and resource. ${ }^{[1]}$ Therefore, it is reasonable to expect higher-education institutions to support their staff. Faculty development initiatives offer staff members the opportunity to gradually obtain the necessary educational competencies in teaching, scholarship and service, which they need to function efficiently and effectively in their roles and responsibilities as educators. ${ }^{[2,3]}$

Over the years, numerous studies using both quantitative and qualitative methodologies have characterised and described the orientation, support and development of new staff members in academia. A few key authors in the field, primarily in the USA, include Boice, ${ }^{[4]}$ Boyd, ${ }^{[5]}$ Carney et al., ${ }^{[6]}$ Chauvin et al. ${ }^{[7]}$ and Rice et al. ${ }^{[8]}$ The focus of research on new staff development varies, from preparing (including orientating) them to get off to a good start ${ }^{[4,7,8]}$ and supporting them, with a specific focus on addressing their experience of stress caused by the demands of rapid adaptation to their new roles and/or experiences related to conflicting professional responsibilities, ${ }^{[8,9]}$ to how to be socialised in academia. ${ }^{[2]}$ Many orientation initiatives include a focus on mentor-mentee relationships to support and develop newly appointed academics. ${ }^{[10]}$ Research on continued improvement of orientation initiatives is also available, as are studies considering new staff members' reflections on, perceptions of and attitudes towards orientation activities, ${ }^{[2]}$ and how to improve faculty development services offered to newly appointed academics. ${ }^{[6,11]}$ Faculty developers at medical schools in South Africa (SA) can make use of existing models and practices to develop and implement faculty development programmes and services; ${ }^{[12]}$ however, it is critical to explore the potentially unique needs of their own academic staff and tailor faculty development initiatives accordingly.

In a study of new faculty in North American medical schools, ${ }^{[7]}$ the researchers examined new faculty orientation, and concluded that there were no conclusive 'best practices' for presenting faculty development services. However, factors that appeared to support satisfactory orientation of new staff across the medical schools included setting explicit learning outcomes; easily accessible information resources; multiple sessions distributed over time; opportunities to build collegial relationships; programme evaluation, with a focus on processes and overall impact; and explicit faculty commitment and support. Furthermore, the literature shows that ongoing training experiences offered over a period of time, or scaffolded learning opportunities, are more effective than once-off offerings. ${ }^{[3]}$ The training can be centralised (to include all disciplines in a faculty or university) or decentralised (to have the same disciplines together). All of these factors are regarded to be important and should be considered when planning for and presenting orientation initiatives to newcomers to medical education.

In addition to learning needs and the abovementioned factors, faculty developers should consider the specific target population. Newly appointed academics in medical education generally possess professional or health sciences degrees in various disciplines (making them content or discipline experts); they do not always possess the required pedagogic and andragogic competencies to teach effectively in a contemporary medical education setting. Even for candidates with prior teaching experience, one should examine whether their experience is sufficient in light of the rapid changes 
in higher education, including medical education, which have brought about multiple opportunities and challenges for academic staff. Teaching-learning concepts have changed, from traditional ways of teaching to more authentic approaches, which advocate for learner-centredness, active learning, higherorder thinking and skills and competency-driven educational principles. The use of technology in education has also increased and the platform grows daily, with new concepts and approaches for improving engagement with the current generation of students and contributing to their learning experiences in medical education. ${ }^{[13]}$

Orientation and support initiatives should be aimed at newly appointed academics, who are adult learners, to avoid stagnation; instead, they should be flexible and regularly updated with regard to a specific target population and the continuously changing higher-education environment. For example, faculty developers at Ben-Gurion University of the Negev, Israel, draw upon the prior knowledge and experience of newly appointed staff by using facilitated inter-professional small-group activities. In this innovative approach to orientating new staff, a series of interactive activities involve all participants to guide and support learning and create opportunities for course facilitators to consolidate knowledge on a particular subject and add additional and new knowledge or clarify misconceptions. ${ }^{[14]}$ This perspective raises the question of whether approaches to new academic staff orientation that are more engaging are more effective at helping them learn than the long-established model of transmitting information through presentations and lecture-based models. SA authors Kridiotis and van $\mathrm{Wyk}^{[15]}$ included a peer- and educationist-evaluated microteaching experience in an orientation programme. The engagement between the group of newly appointed academic staff members (peers) and educationists through evaluating the microteaching sessions and presenting verbal feedback in the larger group led to reflections, stating that the activity was valuable, as the group subsequently felt more confident as lecturers and more competent to implement newly acquired teaching skills.

Our contribution to the literature on new academic staff orientation is, therefore, based on findings from research conducted on the orientation, support and continued development of newly appointed academics in medical education. We focus on an SA university, where the Division Health Sciences Education of the Faculty of Health Sciences had established an educational development course aimed at newly appointed academics. Over time, however, there were variations in the course duration, topics covered and presentation styles and teaching-learning methods used by the course presenters. Furthermore, centralised training has always been offered to newly appointed academic staff members in the Faculty of Health Sciences, including academic staff members from all disciplines and professions who were appointed on all academic levels in the health sciences. Questions regarding the overall effectiveness of the programme led to a qualitative enquiry into newly appointed academics' experiences after successfully completing the course. The enquiry was initiated with the primary intent of stimulating improvements to our programme, but also to share the findings that might have broader application to other faculty development programmes for newly appointed academics in medical education.

\section{Background to the course for newly appointed lecturers}

A course for newly appointed lecturers has been offered in the Faculty of Health Sciences, University of the Free State, Bloemfontein, SA since
1992. The foundation of this course has always been soundly grounded in offering staff members basic knowledge and skills required to teach and assess student learning in medical education. The course has always been centralised, i.e. one course was offered to all newly appointed academic staff members in the Faculty of Health Sciences, regardless of their discipline or type of appointment. Attendance was voluntary and senior staff were allowed to participate in the course to refresh their knowledge and skills. This course ran intermittently, usually twice a year, and was spread over 2 - 3 days, covering 20 hours of training. From 2011 to 2013, the course was presented once a year and extended over 1 - 3 days ( 2 days in 2011, 1 day in 2012 and 3 days in 2013). Both the 2011 and 2013 courses were delivered in a venue in the faculty buildings, while the 2011 course was offered at an off-campus venue. The course was funded by the Division Health Sciences Education (funding obtained from the Faculty of Health Sciences). For these 3 years, the planning, co-ordination and facilitation of the course were managed by an academic staff member qualified in the field of health professions education. The individual sessions were presented by senior staff members, of whom many also hold degrees in health professions education.

Educational topics in the 2011 and 2012 programmes included the roles of the lecturer, introduction to teaching-learning, with a focus on specific educational methods (e.g. lecturing, group work, community-based education, service learning, e-learning and use of technology), assessment, student support and, to a limited extent, personal and professional development topics (e.g. time management, self-knowledge and performance management).

In the 2013 course, consideration was given to including some factors recommended by Chauvin et al..$^{[7]}$ This was approached as follows: (i) 'explicit faculty commitment and support' was ensured by including the dean of the faculty in the course, giving a word of welcome and a presentation on the faculty and university structures; (ii) 'opportunities to build collegial relationships' was elicited by demonstrating simulation and a training method - the course participants simulated patients in role-plays, coupled with discussions and debriefing activities; it included an interactive microteaching activity, which was found to be successful in this setting; ${ }^{[15]}$ and (iii) distributing to each participant a resource file containing copies of all the PowerPoint presentations, additional notes, articles or other interesting sources and information regarding faculty development services, thereby ensuring 'easily accessible information resources'.

Over the 3-year period, the course evaluation focused only on identifying participant satisfaction and no further research was done in this setting. This led to our research enquiry, i.e. to establish which experiences of newly appointed academic staff members followed their participation in the 3-day orientation course. The research formed part of a $\mathrm{PhD}$ study conducted between 2014 and 2016.

\section{Methods \\ Research design}

A phenomenological research design was used, in which focus group interviews were conducted to describe the lived experiences of course participants as they relate to a centralised course for newly appointed lecturers at the Faculty of Health Sciences.

\section{Ethical approval}

Ethical approval to conduct the study was obtained from the Health Sciences Research Ethics Committee, University of the Free State (ref. no. ECUFS 213/2013). 


\section{Participants}

Academic staff members, from junior lecturer to professor, who were employed permanently or on contract and had completed the Faculty of Health Sciences course for newly appointed lecturers during 2011, 2012 or 2013, were included in the study. The potential sample comprised 45 eligible academics, of whom 42 worked at the university at the time of this study - between 2014 and 2015. There was a 43\% response rate (participants, $N=18$ ). Some reasons for non-participation included busy schedules, being short staffed in clinics and academic departments, and being unavailable owing to attendance of conferences.

\section{Data collection}

Eligible academic staff members were personally invited by email and/or telephonically to participate in the study. The focus group interviews were conducted in a neutral location, i.e. a conference room in the faculty's skills and simulation unit. An independent observer managed the logistical aspects on the day of the interviews, which included obtaining consent. An independent, experienced focus group interviewer facilitated the groups. The principal investigator, who was a course presenter, was not present during the interviews, thereby allowing participants to speak freely about their experience of having completed the course. Four focus group interviews were conducted, each group being representative of participants who had completed the 2011, 2012 and 2013 courses. Each interview lasted 45 - 60 minutes.

Two topics were discussed in the focus groups. The first focused on participants' experiences of the faculty-specific course for newly appointed lecturers: 'What were your experiences of the newly appointed lecturers' course that you attended in the Faculty of Health Sciences?' The second topic involved a closer look at the course content and educational development needs. Two questions with some probes were used: (i) 'As a newly appointed lecturer, what educational needs should have been addressed in the newly appointed lecturers' course (consider what you required, as a newly appointed lecturer, to successfully do your job)?'; and (ii) 'What topics that were included in the newly appointed lecturers' course that you completed, should have been offered in more depth?' The questions to the focus group were self-compiled, guided by the specific research objective, to describe the experiences of newly appointed academic staff members after their participation in the course.

Video and audio recordings were used for the transcription process. The videos enabled the researcher, group participants and a co-coder to revisit the interviews to gain a better sense of group interactions and non-verbal communication. This contributed to the trustworthiness of the transcribed (e.g. the video was consulted to transcribe sections where the voice recording was inaudible), analysed and interpreted data. The transcriptions were done by the principal investigator and validated by the facilitator, independent observer and several focus group interview participants.

\section{Data analysis}

Data management and analysis were done in a systematic and sequential manner, following a 5-phase continuum of analysis process, as described by Rabiee: ${ }^{[16]}$ (i) becoming familiar with the raw data by re-reading the transcripts; (ii) identifying a draft thematic framework by focusing on what was said and the topics discussed in each group, and deriving a theoretical concept from this; (iii) indexing, by referring back to the raw data, noting and highlighting quotes related to the thematic framework; (iv) charting (lifting out) the quotes into a single Microsoft Word document; and ( $v$ ) mapping or ordering the data under the specific focus areas, themes and categories as identified. The analysis was co-coded by the focus group interview facilitator.

\section{Results and discussion}

Key findings that pertain to the participants' overall experiences of the course and the lessons learnt are described under the following subheadings: overall experience; orientation structure; active learning practices; and value of faculty professional development throughout one's career. Participant responses extracted from the research data are presented verbatim (where applicable). We also refer to the literature on new faculty development that supports or diverges from our findings.

\section{Overall experience}

The overall experiences of attendees completing this course were positive, and include both content and social-emotional outcomes. First, the group, as newly appointed academics, reported that they generally had no or very little teaching experience, and that they initially lacked knowledge of important medical education concepts, including educational terminology:

'Yes look, a person must just always remember this is the first time that we step into this higher education, like the lingo that we use that we are completely inexperienced in.' (D1.28)

'They talk about (educational) terminology where you had [before the course] no frame of reference where that terminology fits in.' (H2.85)

Participants reported the purpose of the course as clarifying expectations that the faculty had regarding their academic roles. Furthermore, the participants experienced the purpose of the course as providing a solid base of knowledge with regard to teaching and learning as they started their teaching careers:

'The orientation session ... gave me a better idea of what the faculty thoughts are around being a lecturer and where the faculty wants to move in terms of the training of students.' (E1.4)

'This course helps you to give you that necessary background to move from the clinical set-up to the lecture hall.' (G2.11)

'Because I don't come from an educational background and I know nothing about the theories of education; they inform you about all these theories and methods ... it is there where you bring your practical or your content [referring to discipline knowledge], and now you must fuse it with the educational methods.' (H2.28)

Researchers such as Gale ${ }^{[17]}$ observed that many newly appointed academics enter the academic environment with knowledge of the academic realm, gained on the 'other side of the fence', having been students themselves. Gale ${ }^{[17]}$ suggests that this experience provides a very limited view of the actual role of academics. Our research shows that this shortcoming was addressed in our orientation initiative by including it as an explicit course outcome, a factor supporting satisfaction in orientation programmes ${ }^{[7]}$ under the topic 'The roles of the lecturer'.

Earlier research that investigated the experiences of novice and junior faculty members commonly reported that new staff members need to gain acceptance from their colleagues and that junior faculty 'cannot flourish 
in isolation. ${ }^{[4]}$ Extended perceived thoughts of 'feeling like a small fish in a big pond ${ }^{[5]}$ and feeling isolated ${ }^{[4]}$ and anxious ${ }^{[9]}$ may hinder the timely incorporation of a new staff member into a team of colleagues. In our approach to orientate newly appointed staff members, such academics revealed a twofold socially orientated benefit of the initiative. Participants expressed appreciation for the opportunity to meet other newly appointed academics. This gave them a sense of belonging and of feeling less isolated. They also valued meeting more experienced academics and having the opportunity to learn from them:

'It is nice to meet all the new staff and see that we have the same fears and uncertainties.' (L3.10)

'We are isolated, we don't know anybody else, so it was nice for me to meet other people in other disciplines.' (G2.63)

'It is nice to also [learn] from the different departments how they experience their challenges for giving lectures or how to handle a clinical case' (F2.29) 'I found it very interesting to learn from the more experienced colleagues ... and you can get some tips from them.' (G2.63)

\section{Orientation structure}

We agree with Chauvin et al. ${ }^{[7]}$ that there seems to be no single 'golden standard' for the most efficient and effective way to orientate, support and develop newly appointed academics in medical education. We discovered that structure is possibly highly context sensitive. For example, in our setting, we found that a centralised approach to the orientation initiative supported its effectiveness. Our results showed that the benefit of our service being centralised was that it provided an opportunity for new staff members, as a uniform group, to meet peers and feel less isolated. In our case, this is critically important, because our faculty comprises 5 schools, some housed in separate buildings on campus, and some individual departments of schools housed off campus in government hospitals:

'We are not even one faculty here, one building, we sit at Oranje Hospital, so this makes it more difficult in terms of just the logistics and so it helps significantly if, at least, you just know when you come here to whom you must go, who you must see.' (R4.63)

'We are isolated, we don't know anybody else, so it was nice for me to meet other people in other disciplines.' (G2.63)

'It was nice to meet other new lecturers ... just to get to know other people in the faculty.' (M3.9)

This centralised approach led to observations of strengthened collegial relationships among academics who completed the course together. Jarvis ${ }^{[18]}$ considers collegiality to be one of the most important aspects of faculty career development. Strengthened collegial relationships were also observed in a study conducted by Pololi and Frankel, ${ }^{[19]}$ who investigated centralised faculty development initiatives at their institution. Our study furthermore found that professional friendships formed, and we observed colleagues from different disciplines in health sciences working together. For example, participants reported that they referred patients between and across disciplines and professions, taught students from different professions simultaneously, and created research collaborations as a result of their interactions in our orientation course. Sorcinelli ${ }^{[20]}$ reiterated the important role that faculty development programmes can play in encouraging staff involvement in engagements between disciplines. A decentralised faculty development approach may not guarantee the benefit of such engagement.
Despite the efficacy of a centralised approach, our study found that there could be benefits to decentralising a certain aspect of the orientation. This might include focused sessions or learning communities that respond to different appointment types and practices in the various disciplines in health sciences:

'Certain things work differently at the School of Nursing than at Medicine.' (O4.56)

'I think there is also a difference between the clinical guys that work in the wards and hospitals with the students and lecturers in the classroom. It boils down to different methods of presentation and assessment ... apply more specifically to the different disciplines and then also to the different settings within specific fields.' (B1.29)

With this in mind, there is scope for school and departmental faculty development initiatives aimed at the newly appointed academic. For new academics to contribute confidently and competently as scholars within their specific departments, Jawit ${ }^{[21]}$ recommended that new academic staff members engage with communities of practice within their specific departments. This will help new academics to acquire the necessary knowledge and skills - 'know how' of educational practices and approaches in a specific department. Such initiatives should be focused on particular learning requirements of the individual school or department, and should consider prior learning and experiences. ${ }^{[14]}$ A review of staff development models in the health sciences by Lancaster et al. ${ }^{[22]}$ highlighted the benefit of a faculty learning community, i.e. it offers continuing educational development opportunities on a platform where pedagogical practices are shared between colleagues. This is an area for improvement, which this study identified for our specific orientation programme.

\section{Active learning practices}

Another focus of the discussions was the approach taken to presenting the orientation course. Traditionally, the course for newly appointed lecturers in the Faculty of Health Sciences followed a teacher-centred approach. This involved the educationalist identifying a series of topics and then presenting these to medical educators, mainly through a traditional educational method, e.g. using a lecture with slides or hosting a teacher-centred panel discussion. In the past, this approach would have been regarded as the most appropriate, and it was even considered as successful. However, in a changing higher-education environment that emphasises engaged learning for students, the question is whether this is still the best approach to faculty learning - our answer is that it is not. Constructive criticism from a participant in one of the focus group interviews presented food for thought for the course co-ordinator and presenters. The participant noted the following:

'I always feel a bit odd when people tell me about the means for adult education [how to teach in a higher education setting] ... and they do that in a format of a 45-minute formal lecture of pop one slide, pop one slide, pop one slide, and this is how you should teach, next pop another slide ... The context does not match the methodology of how it is presented, you know, and I remember within another context, a guy, the instructor, I really enjoyed it [referring to the instructor's presentation], because as he was telling you what you needed to do, he was actually doing it with the group, so then it became authentic. (C1.34) 
From this response we learnt that it is not useful only to tell an audience about a specific teaching technique or method, but that our adult learners want to obtain new knowledge and skills through demonstrations that allow for active engagement with the instructor and other students. For example, during our course, there was a bedside teaching session that was demonstrated in our simulation and skills unit that elicited positive responses, such as the following:

'We experienced bedside teaching in the simulation unit where we, all the participants, were around the bed. They had an SP [simulated patient] in the bed and a doctor demonstrated how to teach at a patient's bedside using the participants as students.' (G2.25)

In this session and similar ones we experienced that this approach, which was more practical and hands-on, inspired our newly appointed academics to make use of the teaching-learning strategies and methods that were demonstrated. Over the past 5 years, the presentation style of this course has evolved to become more learner-centred, and presenters have revised sessions to create more of a workshop format, comprising a theoretical followed by a practical component that involves the learners. We started using a similar approach to that described by Benor ${ }^{[14]}$ at Ben Gurion University of the Negev. The key is to make use of all the knowledge and expertise of medical education faculty, as well as of staff of the greater faculty, to scaffold learning.

In accordance with the proverb that states, tell me, and I forget, show me, and I remember, involve me, and I understand, we made a further improvement to our course by offering participants the opportunity to apply their newly acquired knowledge and skills in practice. This was done by incorporating a peer- and educationist-evaluated and video-recorded microteaching activity on the final day of the course. Microteaching is a simulated teaching exercise during which participants present a teaching session to an audience that represents students; this activity is useful, as the audience provides instant feedback to the lecturer. ${ }^{[23]}$ Reflections of our course participants indicated that they found the experience enjoyable. ${ }^{[15]}$ Furthermore, their opinion of the activity was that it offered definite benefits through learning from others and obtaining constructive feedback:

'After the course, they sent us the responses of the evaluation forms [of the microteaching session] - there was a lot of qualitative quotes. It was really an experience, now, afterwards, to go through that again, it's like feedback you can learn from, from how others experienced it [referring to their teaching session presented to the peers and educationists] and how they saw it.' (I3.173)

\section{Value of faculty professional development throughout one's career}

Newly appointed academics agreed that, having attended our course, they realised the value of participating in faculty development. There was strong agreement that academics should be accountable for their own continued learning, especially in relation to the roles and responsibilities of a teacher. Examples of participants' responses are the following:

'Something that I just realised is that the onus rests much more on myself. Yes, orientation is one thing, but that one is made more aware that it's not just a once off, you must make time ... perhaps emphasise more the fact that this is not only just the beginning, please remain involved [the participant referred to continuing to participate in faculty development opportunities offered in the faculty]'. (N4.83)
'Yes, I actually agree, because for me it is really worth it and the quality of the training that the faculty presents is good ... it is a responsibility from yourself also to know what is available and to have a programme [faculty development programme], and then to make time.' (P4.83)

Coaldrake and Stedman ${ }^{[24]}$ refer to the need for greater accountability and quality teaching in higher education, which can only be achieved through the upkeep and improvement of educational competencies. It was, therefore, beneficial to follow up this discussion in our study. We believe that our orientation initiatives fostered a sense of responsibility to continue with training that contributed to a positive attitude towards faculty development.

Regarding continuing development and support for senior staff, there were discussions in the focus groups about either including senior staff as course participants in orientation initiatives for newly appointed academics or have separate, focused refresher initiatives for such a cohort. This suggestion relates to new and innovative educational practices for the health professions and technology to enhance teaching practices that become available regularly. Therefore, academics in the health professions should have the opportunity to continuously update, not only their content knowledge, but also their pedagogical knowledge and skills:

'New things come out, things that they are not even aware of - so I think it will be very valuable if they could have a refresher course for senior lecturers, or for people who have been there for very long.' (A1.77-79)

'So, maybe we can do a new lecturers' course for old lecturers, it's just to keep everybody updated.' (G2.106)

'It should be mandatory, like a first-aid course that you have to renew, so it should be mandatory that you go every so many years.' (H2.108)

Our findings showed that a senior colleague with 10 years' teaching experience who completed our orientation course, reported doing so to refresh and update his educational competencies. He described his experience as follows:

'I enjoyed it, even doing it 10 years after I started as a lecturer, I think that it is really valuable and, even after 10 years, I learnt a lot.' (G2.106)

This comment suggests that even an experienced academic can find an orientation course to be a valuable learning opportunity. Another benefit we found with the participation of more experienced or senior staff (someone who had worked as a medical educator for a while) in the orientation course was that they had a better understanding of the functioning of the institution and related differently to some of the information provided; they even played a mentor/coaching role in the group. We learnt that orientation initiatives should not have restrictions on who may participate. When senior faculty members participate in the course, there is great benefit in bringing along their self-learnt experience acquired over time in teaching; at the same time they will be able to update their knowledge and skills regarding any new teaching methods and modern technologies.

One of our limitations regarding the topic of professional development throughout a career is that the role of mentoring in the successful orientation of new staff was not explicitly probed during the focus group interviews or discussed by the participants. This could be because a formal mentoring programme is not yet fully established in our faculty development services. There are, however, mentor-mentee relationships in some departments of the Faculty of Health Sciences. Our study found that new staff members regarded exposure to peers and senior colleagues as 
important, and they valued learning from all their colleagues involved in the orientation programme. We recommend that our faculty development service encourages the adoption of a mutual mentoring model for new faculty members. With this type of mentoring model, the mentee will have multiple self-identified mentors, who can offer support in all their roles and responsibilities in academia. ${ }^{[25]}$ This will ensure continued support and development for newly appointed academics, even after they have completed a formal orientation programme.

\section{Conclusions}

The findings of our research leave little doubt that the orientation course was a success, and it will continue to be refined and improved. We also learnt several important lessons from our study, which we share as considerations for other such faculty development endeavours.

First, our centralised faculty development approach offered a number of benefits to the group of newly appointed academics. These included opportunities for supportive peer interaction, collaborations, building and strengthening collegial relationships, and also learning from experienced senior colleagues. Attention should also be given to specific education-related learning requirements and practices of individual schools and departments, where there is space for decentralisation of several aspects of orientation. One evidence-based approach to addressing these requirements is to establish communities of practice within schools and departments in the Faculty of Health Sciences. Another evidence-based approach includes the adoption of a mutual mentoring initiative for newly appointed academic staff members.

Second, we learnt that, for a faculty development initiative to be effective, staff should gain insight into how to effectively make use of innovative, learner-centred teaching-learning strategies, such as simulation, which is one form of experiential learning. In this way, staff can experience the reality of a scenario and gather meaning from it, instead of passively listening to a lecture or panel discussion. Furthermore, by including microteaching in an orientation programme, participants will be more confident and better equipped, and have the opportunity to engage with the learning material and use it in a constructive and supportive learning environment.

Finally, faculty developers should foster a culture of accountability towards continued faculty professional development throughout a career the importance of this accountability should be instilled in academic staff early in their career. This could be fostered by an orientation programme aimed at newly appointed academic staff members.

Moving forward, we recommend continued research regarding our programme by focusing on its contributions and strengths. Some areas of research could include measuring knowledge and skills of participants before and after the orientation, or comparing a measurement of the effects of the orientation with the performance management of academic staff members who complete the orientation and those who do not. Evidence should be used to improve the programme and to contribute to the body of knowledge.

We, therefore, conclude by advising continued research in the field, especially in the context of medical education at SA universities. We also recommend collaboration among faculty developers at different SA universities.
Declaration. None.

Acknowledgements. Thanks is due to the academic staff members who participated in the study and to Dr Mary Deane Sorcinelli of the University of Massachusetts, Amherst, USA, for reading the article and offering insightful comments.

Author contributions. CvW: principal investigator of the research and reponsible for writing the article; MMN and GJvZ: contributed as research promotors, as well as to the conceptualisation and completion of the article.

Funding. Health and Welfare Sector Education and Training Authority (HWSETA); Office of the Dean, Faculty of Health Sciences, University of the Free State (UFS) for funding to benchmark the research at conferences; and staff doctoral study support funding, Postgraduate School, UFS.

Conflicts of interest. None.

EDUCBA. Why are employees the most valuable intangible assets? EDUCBA Business Blog Tutorials. https:/ www.educba.com/employee-most-valuable-intangible-assets/ (accessed 15 October 2018).

2. Puri A, Graves D, Lowenstein A, Hsu L. New faculty's perceptions of faculty development initiatives at small teaching institutions. ISRN Educ 2012:1-9. https://doi.org/10.5402/2012/726270

3. Steinert Y. Faculty Development in the Health Professions. A Focus on Research and Practice. Dordrecht: Springer, 2014:1-446.

4. Boice R. The New Faculty Member. 1st ed. San Francisco, CA: Jossey-Bass, 1992:336.

5. Boyd P. Academic induction for professional educators: Supporting the workplace learning of newly appointed lecturers in teacher and nurse education. Int J Acad Develop 2014:15(2):155-165. https://doi. org $/ 10.1080 / 13601441003738368$

6. Carney AE, Bacig KZ, Helms RM. New faculty orientation at the University of Minnesota, Twin Cities, USA. Conference paper. What Works Conference, Paris, France, 3 - 4 September 2007. www.academic.umn.edu/ newfaculty/france07.pdf (accessed November 2018).

7. Chauvin SW, Anderson W, Mylona E, Greenberg R, Yang T. New faculty orientation in north American medical schools. Teach Learn Med 2013;25(3):185-190. https:// doi.org/10.1080/10401334.2013.797345

8. Rice RE, Sorcinelli MD, Austin AE. Heading New Voices: Academic Careers for a New Generation. Washington,

DC: American Association for Higher Education, 2000. https://www.umb.edu/editor_uploads/images/ofd/ DC: American Association for Higher Education, 2000. https://www.umb.edu/editor

9. Menges RJ. Faculty in New Jobs: A Guide to Settling In, Becomming Established, and Building Institutional Support. San Francisco, CA: Jossey-Bass, 1999:368

0. Beane-Katner L. Anchoring a mentoring network in a new faculty development program. Ment Tuto 2014;22(2):91-103. https://doi.org/10.1080/13611267.2014.902558

1. Boyden KM. Development of new faculty in higher education. J Prof Nurse 2000;16(2):104-111. https://doi.org/ 10.1016/88755-7223(00)80023-X

12. McLean M, Cilliers F, van Wyk JM. AMEE Educational Guide 36. Faculty development: Yesterday, today and tomorrow. Med Teach 2008;30:555-584. https://doi.org/10.1080/01421590802109834

13. Frenk J, Chen L, Bhutta ZA, et al. Health professionals for a new century: Transforming education to strengthen health systems in an interdependent world. Lancet 2010;376(9756):1923-1958. https://doi.org/10.1016/S01406736(10)61854-5

14. Benor DE. Faculty development, teacher training and teacher accreditation in medical education: Twenty years from now. Med Teach 2000;22(5):503-512. https://doi.org/10.1080/01421590050110795

15. Kridiotis C, van Wyk C. A critical reflection by participants on microteaching as a learning experience for newly appointed health professions educators. Afr J Health Professions Educ 2019;11(2):41-46. https://doi.org/10.7196/ AJHPE.2019.v1li2.1103

16. Rabiee F. Focus group interviews and data analysis. Proc Nutri Soc 2004;63:655-660. https://doi.org/10.1079/ PNS2004399

7. Gale H. The reluctant academic: Early-career academics in a teaching-orientated university. Int J Acad Develop 2011;16(3):215-227. https://doi.org/10.1080/1360144X.2011.596705

18. Jarvis D. Junior Faculty Development. A Handbook. New York: Modern Language Association of America, 1991:128.

19. Pololi LH, Frankel RM. Humanising medical education through faculty development: Linking self-awareness and teaching skills. Med Educ 2005;39:154-162. https://doi.org/10.1111/j.1365-2929.2004.02065.x

20. Sorcinelli MD. Faculty Development: The Challenge Going Forward. Peer Review Ass Am College Univer 2007;9(4):4-8.

21. Jawitz J. New academics negotiating communities of practice: Learning to swim with the big fish. Teach High Educ 2007;12(2):185-197. https://doi.org/10.1080/13562510701191943

22. Lancaster JW, Stein SM, MacLean LG, et al. Faculty development program models to advance teaching and learning within health science programs. Am J Pharm Educ 2014;78(5):99. https://doi.org/10.5688/ajpe78599

23. Donnelly R, Fitzmaurice M. Towards productive reflective practice in microteaching. Innov Educ Train Intern 2011;48(3):335-346.

24. Coaldrake P, Stedman L. On the Brink: Australia’s Universities Confronting Their Future. St. Lucia: University of Queenstown Press, 1998

25. Yun JH, Baldi B, Sorcinelli MD. Mutual mentoring for early-career and underrepresented faculty: Model, research, and practice. Innov High Educ 2016;41(5):441-451. https://doi.org/10.107/s10755-016-9359-6

Accepted 4 December 2018. 